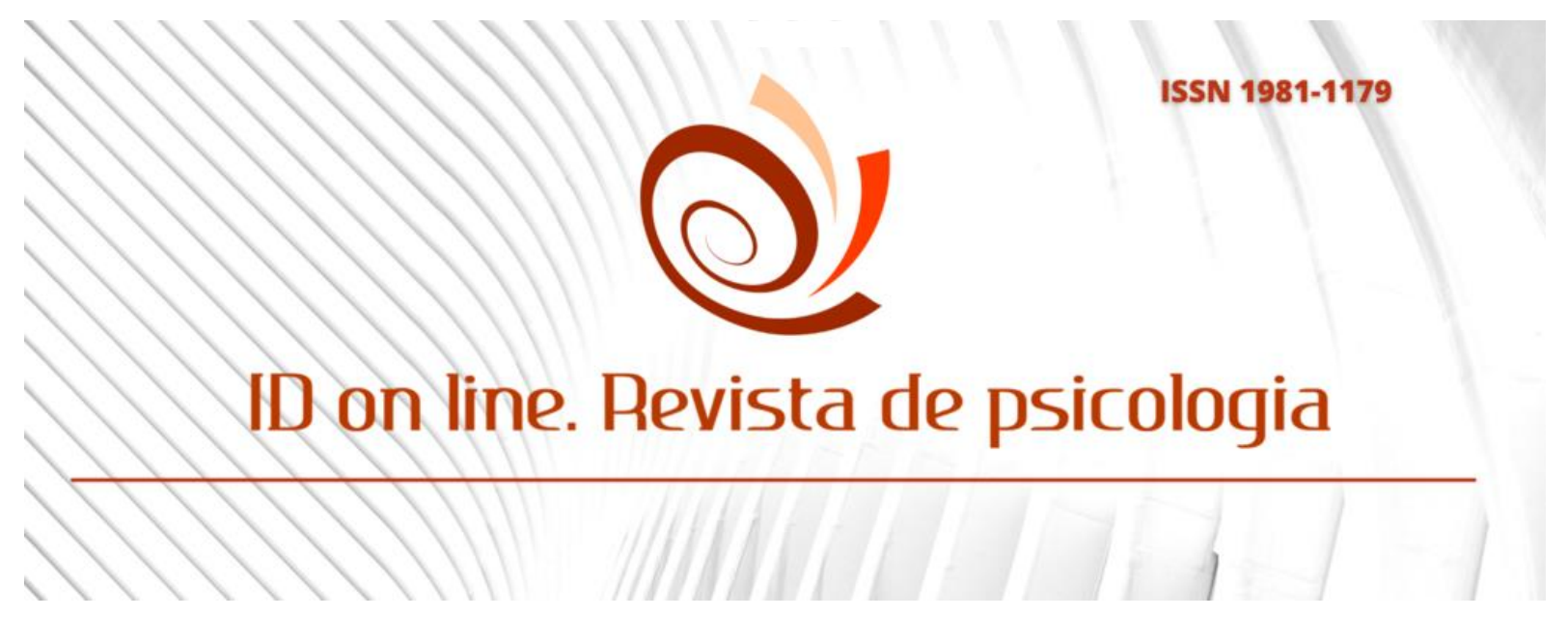

DOI: 10.14295/idonline.v15i57.3250

Artigo

\title{
Os Desafios do Professor no Século XXI: A Tecnologia como uma Aliada no Processo Ensino e Aprendizagem
}

\author{
Felipe Ribeiro da Silva ${ }^{1}$; Fabiana Alves de Lucena ${ }^{2}$; Maria do Socorro Cordeiro de Sousa ${ }^{3}$
}

\begin{abstract}
Resumo: O papel do professor no processo ensino e aprendizagem é muito importante, sendo sua a missão de transmitir os conteúdos e de contribuir de forma significativa com o desenvolvimento do estudante, exercendo assim múltiplos papéis em sala de aula. Nesse contexto, merece destaque a metodologia de ensino dos professores, a qual vem sofrendo mudanças ao longo do tempo, por isso estes precisam estar constantemente adequando seus planejamentos as necessidades do alunado, tanto em conjunto como de modo individual. Essas mudanças tiveram mais um atenuante ao abordar a questão da pandemia do novo coronavírus (SARS-CoV-2) que, em meados de março de 2019, ocasionou o fechamento das escolas e o distanciamento das aulas presenciais, tornando obrigatório a busca por novos métodos para continuar com o processo de ensino e aprendizagem mesmo fora do seu espaço habitual. Destarte, o professor precisou de imediato adequar-se a nova realidade, introduzindo em suas aulas o uso da tecnologia, fomentando, com isso, o ensino remoto. Partindo desse cenário, o presente trabalho tem por objetivos analisar quais os desafios que o professor vem enfrentando em relação às novas formas de ensino durante a pandemia e verificar como a tecnologia tem auxiliado a docência. A justificativa para a escolha desse tema pauta-se na relevância de discutir as novas formas de ensino trazidas pela realidade vivenciada devido ao coronavírus, sendo uma temática importante para discussões como discente de Pedagogia. Para tanto, os principais autores que embasaram o trabalho foram: Moren e Santos (2011); Novoa (2017); Aguiar (2020); Calejon e Brito (2020); Cordeiro (2020); Melo (2020); Oliveira (2020); e Peres (2020). Já a metodologia utilizada foi a análise de arquivos publicados por autores que trataram do tema, logo, se constituindo de fontes atuais e se qualificando como uma pesquisa bibliográfica de caráter qualitativo. Deste modo, as contribuições ofertadas pelo artigo constituíram-se como fundamentais para compreender os reflexos ocasionados pela pandemia no contexto educacional, enaltecendo o papel do professor e os desafios enfrentados por ele com o intuito de manter o interesse dos estudantes e a aqualidade do ensino mesmo em face do distanciamento das escolas.
\end{abstract}

Palavras-Chave: Educação. Ensino Remoto. Professor. Pandemia.

\footnotetext{
${ }^{1}$ Aluno do curso de Pedagogia da Faculdade de Ciências Humanas do Sertão Central (FACHUSC); Email: feliperibeirotn@gmail.com;

${ }^{2}$ Especialista em Fisiologia do Exercícios e Grupos Especiais pelo Centro Universitário Dr. Leão Sampaio, Brasil (2011). Professora de Educação Física da Escola de Ensino Fundamental Marieta CallS e Tutora da Universidade Norte do Paraná (UNOPAR) -Polo Brejo Santo-Ce. fabylucenabs@gmail.com

${ }^{3}$ Doutora em Letras pela Universidade do Estado do Rio Grande do Norte (UERN), Pau dos Ferros, Rio Grande do Norte, Brasil. Mestra pela Universidade do Estado do Rio Grande do Norte (UERN), Pau dos Ferros, Rio Grande do Norte, Brasil. E-mail: corrinhacordeiro@gmail.com
}

769 Id on Line Rev. Psic. V.15, N. 57, p. 769-778, Outubro/2021 - Multidisciplinar. ISSN 1981-1179 Edição eletrônica em http://idonline.emnuvens.com.br/id 


\title{
The Teacher's Challenges in the 21st Century: Technology as an ally in the Teaching and Learning Process
}

\begin{abstract}
The teacher's role in the teaching and learning process is very important, and its mission is to transmit the contents and to contribute significantly to the student's development, thus playing multiple roles in the classroom. In this context, the teaching methodology of teachers deserves to be highlighted, which has undergone changes over time, so they need to be constantly adapting their plans to the needs of the students, both together and individually. These changes had one more mitigation when addressing the issue of the new coronavirus pandemic (SARS-CoV-2) which, in mid-March 2019, caused the closing of schools and the distance from in-person classes, making the search for new methods mandatory to continue the teaching and learning process even outside their usual space. Thus, the teacher needed to immediately adapt to the new reality, introducing the use of technology in their classes, thus promoting remote learning. Based on this scenario, this work aims to analyze the challenges that the teacher has been facing in relation to new forms of teaching during the pandemic and to verify how technology has helped teaching. The justification for choosing this theme is based on the relevance of discussing the new forms of teaching brought about by the reality experienced due to the coronavirus, which is an important topic for discussions as a Pedagogy student. Therefore, the main authors who supported the work were: Moren and Santos (2011); Novoa (2017); Aguiar (2020); Calejon and Brito (2020); Lamb (2020); Melo (2020); Oliveira (2020); and Peres (2020). The methodology used was the analysis of files published by authors who dealt with the theme, therefore, constituting current sources and qualifying as a qualitative bibliographic research. Thus, the contributions offered by the article were fundamental to understand the consequences caused by the pandemic in the educational context, extolling the role of the teacher and the challenges faced by him in order to maintain the interest of students and the quality of teaching. given the distance between schools.
\end{abstract}

Keywords: Education. Remote Teaching. Teacher. Pandemic.

\section{Introdução}

O professor é sem dúvidas uma peça fundamental no processo ensino e aprendizagem, pois a missão do docente não é apenas de repassar conteúdos, fórmulas e regras, mas vai muito além, ele precisa desenvolver diversos papéis dentro da sala de aula, bem como saber lidar com cada aluno conforme a sua individualidade.

Ao longo do tempo, esse profissional da educação sentiu-se obrigado a mudar sua didática e metodologia a fim de conseguir engajar-se no mundo moderno, que está em constante movimento e transformação seguindo as mudanças das sociedades. De fato, muitas das concepções tidas pelos mestres há algum tempo, caíram no obsoleto atualmente. Deste modo, foi a partir dessa perspectiva que a inovação e o aperfeiçoamento do seu trabalho tornaram-se tão necessários.

Em meados de 2020, o mundo vivenciou uma realidade considerada atípica, ao se ter início a pandemia do novo coronavírus (SARS-CoV-2), ocasionando inúmeras modificações 
no cotidiano das pessoas, uma delas diz respeito ao fechamento das escolas, em que as aulas passaram a acontecer de maneira remota, o que resultou na adequação dos professores a esta nova realidade.

Tomando como base a atuação do professor na pandemia do Covid 19, o presente trabalho pretende responder os seguintes questionamentos: quais os desafios que o professor tem enfrentado em relação as novas formas de ensino diante do cenário pândemico? E como a tecnologia tem auxiliado na docência nessa questão? Partindo disto, o artigo tem por objetivo principal analisar como se comporta o professor frente aos desafios impostos pelas novas formas de ensino na sociedade atual, destacando a sua relevância no desenvolvimento dasta sociedade e enaltencendo as dificuldades encontradas por ele no processo ensino e aprendizagem mediado pelas tecnologias.

Uma das hipóteses trabalhadas é que os maiores desafios encontrados pelo professor dizem respeito à desvalorização do seu trabalho e à falta de investimentos na área da educação, o que pode, muitas vezes, limitar suas ferramentas de trabalho, e isto se tornou ainda mais perceptível diante do cenário pandêmico atual. Outrossim, as ferramentas tecnológicas tornaram-se partes essenciais da didática do professor moderno, o que implica na carência de domínio básico dessas ferramentas por parte de tantos professores.

A pesquisa consolida-se como bibliográfica, utilizando do método dedutivo, sendo esta de carater qualitativo e exploratório. Sua fundamentação deu-se através da análise de publicações acerca do tema. Os principais autores que embasaram o trabalho foram: Cordeiro (2020); Moren e Santos (2011); Novoa (2017); Aguiar (2020); Peres (2020); Melo (2020); Calejon e Brito (2020) e Oliveira (2020).

A temática discutida neste artigo revela, dentre outras coisas, os paradigmas que se referem ao professor do século XXI, discorrendo sobre as implicações que envolvem a atuação desse professor modeno, suas práticas, as metodologias e, principalmente, os desafios que são enfrentados, aqueles que são reflexos desde o começo da historia, e tantos outros que surgiram ao longo do tempo. Com base nisso, a pesquisa tem muito a contribuir com a abordagem deste tema. 


\section{Metodologia}

O passo a passo do trabalho dividiu-se em etapas. Primeiro foi realizada a escolha do tema e o tipo de metodologia. Após isso, percebeu-se o problema de pesquisa, a hipótese, os objetivos e a busca pelo referencial teórico, momento em que selecionou-se os autores. E, por fim, foi elaborado o resumo contendo as informações mais relevantes do artigo; a introdução que apresenta o tema; a fundamentação teórica que traz o embasamento dos autores; e as considerações finais que apresenta os achados da pesquisa.

A abordagem do trabalho trata-se de uma pesquisa bibliográfica, sendo toda bibliografia pública, por exemplo: revistas, livros, jornais ou outras fontes (MARCONI; LAKATOS, 2011, p. 57). Desta forma, para compor o aporte teórico, foi utilizado a pesquisa em fontes diversas disponíveis em meio impresso e digital, sendo feita a seleção do material adequado para elaboração do artigo.

Assim, a pesquisa bibliográfica "é desenvolvida a partir de material já elaborado, constituído principalmente de livros e artigos científicos" (GIL, 2010, p. 50). É importante analisar as ideias defendidas pelos autores que já pesquisaram sobre a mesma temática discorrida neste artigo, a fim de dispor do maior número de informações possíveis, verificando sempre a veracidade de tais informações.

Ademais, a abordagem qualitativa foi escolhida em razão de que: "proporciona melhor visão e compreensão do problema”. (MALHOTRA; et al, 2010, p. 113). Através dessa abordagem, tornou-se possível ter uma visão melhor sobre o problema foco da pesquisa, compreendo-o mais nitidamente.

\section{O Professor no contexto da Pandemia do Covid 19: desafios e possibilidades}

A pandemia do novo coronavírus (SARS-CoV-2) parou o mundo desde o início de 2020. O isolamento social foi uma das principais medidas tomadas no intuito de conter a disseminação do vírus. Com isso, as escolas tiveram que parar seu funcionamento presencial e, desta forma, adotarem o ensino remoto como um meio para manter suas atividades. Nesse caso, o ensino remoto comporta-se como uma forma de ensino que se dá através de meios tecnológicos (celulares, tablets, computadores), cuja principal ferramenta é a internet.

Em todo o país, as aulas presenciais foram substituídas pelas remotas por meio da portaria de $n^{0} 343$ de 17 de março de 2020 para melhor realização das atividades escolares. 
Desse modo, o Conselho Nacional de Educação (CNE) permitiu que houvesse mudança nos calendários escolares e nas atividades realizadas a fim de atender as necessidades dos alunos. Cabe destacar que essas mudanças levaram em consideração as medidas de distanciamento recomendas pelos órgãos de saúde.

Nesse sentido, o ensino remoto foi uma novidade para todo o âmbito escolar, alunos, professores, gestores, secretários e demais envolvidos na área da educação, pois ninguém estava preparado para essa forma de ensino. Contudo, vale destacar que os pais também sentiram no seu dia a dia a mudança na forma de ensino, visto que, com os filhos precisando estudar em casa, muitos deles tiveram que adequar a sua rotina para acompanhar o estudante. Além disso, é importante mencionar que nem todos os estudantes possuem estrutura para acompanhar as aulas online, uma vez que estes não possuem aparelho de celular ou computador em casa ou não tem acesso à internet.

Segundo Cordeiro (2020), um dos maiores desafios impostos pelo isolamento social diz respeito ao processo ensino e aprendizagem, em que muitos tiveram que reaprender a ensinar e outros reaprender a aprender. É nesse sentido que a figura do professor ganha ainda mais destaque nesse processo, posto que antes da pandemia toda responsabilidade de mediar os conhecimentos do alunado era destinado a ele, no entanto, com as mudanças trazidas pela pandemia, essa responsabilidade foi dividida com terceiros, principalmente os pais e a família.

Diante da nova realidade, houve uma troca entre os espaços de aprendizagem, em que a escola foi substituída pela própria casa do alunado, e as ferramentas de trabalho do professor passaram a ser necessariamente um celular ou computador. Essa troca possibilitou, em alguns casos, a aproximação entre família e escola, levando à compreensão de que a missão de educar não é exclusividade do ambiente escolar.

No que tange as dificuldades vivenciadas pelo professor durante a pandemia, é preciso analisar a sua formação enquanto docente. A esse respeito, Moren e Santos (2011) abordam que a educação brasileira deixa muito a desejar, e isto é decorrente sobretudo do fato de não haver uma formação boa dos docentes, pois eles não são preparados para atuar nas mais diversas situações de ensino. Como um exemplo disso pode-se citar os desafios que tiveram para ministrar suas aulas através dos meios tecnológicos, principalmente os professores com mais tempo de trabalho na educação, uma vez que durante sua formação não tiveram acesso a este tipo de metodologia.

Além da formação, outro fator que compromete o bom trabalho do docente está aliado as condições precárias as quais, muitas vezes, ele está sujeito a realizar seu trabalho. Para 
Novoa (2017), nos últimos anos, a docência tem sido exposta a más condições de trabalho e de vida, cujo resultado vem sendo a desmoralização da classe. Neste contexto, nota-se que a desvalorização desse profissional torna seu trabalho mais dificultoso, não dispondo de ferramentas suficientes para criar planejamentos mais interativos.

Com a atual pandemia, foi perceptível a necessidade de adequação das práticas e metodologias de ensino em tempo hábil, a fim de diminuir os danos causados pelo afastamento das aulas presenciais. Contudo, como afirma Aguiar (2020), o modo de ensino de um professor não pode ser alterado de repente. Sair do seu espaço de atuação, no caso, a sala de aula, e se adequar a outro modo de ensinar, é muito desafiador. Conforme Peres (2020), dar aula por meio de aplicativos requer muita competência e habilidade, pois uma das maiores questões encontradas pelo docente é conseguir manter os alunos concentrados através da tela de um aparelho. Todavia, para Cordeiro (2020), tal realidade que já se tornou parte da rotina escolar, veio para ficar, e o professor terá que implementar, em sua metodologia de ensino, o uso das mídias digitais.

Um fator preocupante ao tratar do ensino remoto refere-se a desigualdade social que, embora sempre seja gritante na sociedade, se tornou ainda mais atenuada dada a pandemia. E as escolas, que exerciam o papel de buscar equiparar os estudantes, comportam-se hoje como um atenuante dessas desigualdades, pois se nota que a aprendizagem do alunado não se comporta da mesma maneira, enquanto alguns conseguem acompanhar as aulas, participar das atividades e manter o ritmo nos estudos, outros não dispõem de internet ou de algum aparelho midiático, fato que não permite a participação deles nas aulas online.

Segundo Aguiar (2020), outro ponto que deve ser abordado é a respeito da facilidade com que o professor da escola particular teve de ministrar suas aulas, visto que a própria escola buscou por recursos que melhorassem a qualidade de transmissão das aulas. Enquanto, nas escolas públicas, os professores tentam fazer o seu melhor com os poucos recursos de que dispõem.

Os professores formam a base do processo educacional, desempenhando o papel fundamental na transmissão de saberes, entretanto, nem sempre são valorizados e reconhecidos como merecem. Durante sua graduação esses profissionais trabalham a parte teórica e prática do curso que escolheram atuar. Eles se preparam para o mesmo contexto, a sala de aula. Dentro as múltiplas situações que podem vivenciar em seu espaço de trabalho, a graduação jamais lhes preparou para viver uma pandemia. Nesse contexto, Peres (2020) aborda que os cursos que formam o docente não se voltam em nenhum momento para atuarem 
em uma pandemia. Sobre isso, Melo (2020) ainda afirma que a docência para a qual as licenciaturas preparam seus licenciandos é aquela exercida dentro de uma sala de aula, com o uso do quadro negro, de livros e do contato real entre professor e alunos. Todavia, eles não são preparados para atuarem no campo virtual, logo, nem a graduação, nem a pós, nem mestrado ou doutorado lhes preparam para esse momento.

Ademais, embora os desafios do professor com a tecnologia venham sendo associados a professores mais velhos, Calejon e Brito (2020) elucidam que, mesmo os professores que possuem familiaridade com a tecnologia, devem passar por capacitações que lhes ensinem a usar os aparelhos da maneira mais correta, almejando uma aprendizagem sadia entre os alunos. Devido ao fato de ser uma realidade atípica, o aspecto idade não difere em muita coisa quanto à necessidade do aprimoramento das técnicas com o uso da tecnologia, valendo tanto professores mais velhos como os mais novos.

É importante discorrer ainda sobre a parte emocional dos educadores, o que tem sido muito alarmante na atualidade. De acordo com Peres (2020), além de todos os desafios impostos ao professor durante a pandemia, alia-se a isso a desestabilidade emocional vivenciada por muitos professores, em razão de que tiveram que sair do seu ambiente de trabalho e se adaptar a uma nova realidade, sem falar das suas preocupações inerentes à aprendizagem dos estudantes terem ampliado. Melo (2020) complementa esse tópico ponderando que, embora esteja com seu emocional fragilizado, o professor carece de ser um ponto de apoio dos alunos, posto que estes também têm apresentado notórios problemas relacionados ao seu emotivo.

Com todos os desafios pelo qual o professor tem passado, Oliveira (2020) destaca o surgimento da necessidade de ele se reinventar na sua profissão, pois muitos docentes utilizavam de metodogias ultrapassadas e viviam na zona de conforto de uma rotina monótona. Contudo, a partir do uso dos meios tecnológicos, todos adquirem múltiplas opções de atividades para explorarem seu campo de ensino e, como menciona Oliveira (2020, p. 39), "Nesse novo ambiente de aprendizagem, o professor precisa ir além, motivar, aguçar a curiosidade, instigar a pesquisa, provocar a reflexão, o desenvolvimento do pensamento crítico".

Sobre o que afirma Oliveira (2020), percebe-se que a pandemia, apesar de trazer reflexos muitos dolorosos e consequências inimagináveis, mudou o conceito de aprendizagem e colocou a figura do professor em um novo cenário, o fazendo rever seus conceitos enquanto docente. Cabe, agora, a todos os envolvidos no sistema educacional, saber fazer bom uso da 
nova realidade da qual se está fazendo parte, uma vez que muitas mudanças acarretadas pela pandemia podem ser permanetes. Assim, novas formas de ministrar as aulas foram introduzidas, as quais levam em consideração que o saber não se constrói apenas dentro da sala de aula, podendo ocupar múltiplos espaços e se desenvolver de diversas formas. Nesse sentido, o professor deve, a partir desta nova realidade, está em constante adequação das suas práticas, objetivando a inovação destas em todas as situações, mesmo aquelas consideradas atípicas, como o caso da pandemia do novo coronavírus (SARS-CoV-2).

\section{Considerações Finais}

Diante do exposto, constata-se que o professor exerce um papel fundamental no que tange ao processo ensino e aprendizagem, isto se reflete nos diferentes papéis que ele exerce em sala de aula, representando um espelho para muitos estudantes. No entanto ao cenário atual vivido em decorrência da pandemia do novo coronavírus (SARS-CoV-2), o trabalho desse profissional passou por notórias mudanças, surgindo a partir de então uma infinita quantidade de desafios e possibilidades para o docente.

As escolas fechadas trouxeram uma realidade inimaginável para o cotidiano das pessoas, alterando a rotina de professores, alunos, pais, bem como de toda a sociedade, ocasionando assim a necessidade de novas metodologias que pudessem de forma eficaz minimizar os efeitos desse distanciamento das instituições de ensino.

Em um primeiro momento, todos que compõem a educação no país se sentiram perdidos, e para o professor a resposta a novas formas de ensino teve que ser de imediata, trazendo para o seu cotidiano o uso da tecnologia como ferramenta primordial para o ensino remoto. Nesse viés, as aulas online foram consideradas o método mais plausível para que se continuasse o processo de ensino e aprendizagem em ambientes fora da escola; no entanto, a inserção da tecnologia no planejamento dos docentes foi um desafio para muitos deles, que eram distantes do uso dos meios digitais, resumindo suas aulas a metodologias antigas, como o uso do livro e do quadro negro.

Dessa maneira, além de todas as preocupações resultantes do proprio período de pandemia, a educação teve que em pouco tempo reformular a forma de ensino, substituindo desde o quadro negro pelo computador até a sala de aula pela sala de casa, tudo para tentar diminuir os impactos dessa nova realidade na aprendizagem do alunado.

Os professores tiveram que lidarem, ainda, com o fato de nem todos os aluos 
possuírem condições de participar das auals através da internet, o que corrobora com a necessidade de diferentes planejamentos, a fim de fornecerem as mesmas condições de estudo para todos e, por consequência, evitarem contribuir com as desigualdades sociais.

Destarte, é importante mencionar que esses professores tiveram, também, a possibilidade de extrair novos conhecimentos a partir do atual momento vivido, uma vez que a pandemia os tiraram da zona de conforto, fazendo sempre uso da mesma metodologia, necessitando assim de um novo lugar para o docente, em que ele não apenas é transmissor do saber, mas também um aprendiz de novos saberes.

Portanto, muitas mudanças advindas da pandemia no cenário educacional, provavelmente serão permanentes, por exemplo: o uso da tecnologia nas escolas como uma ferramenta facilitadora do processo ensino e aprendizagem, o ensino híbrido, a análise do individualismo, entre outras mudanças que, certamente, contribuirão para o ofereceminto de uma educação melhor no país.

\section{Referências}

AGUIAR, F. R. M. Pandemia da covid-19 e demandas de atuação docente. Revista Diálogos Acadêmicos, v. 9, n. 1, 2020.

CALEJON, L. M. C.; BRITO, A de S. Entre a pandemia e o pandemônio: umareflexão no campo da educação. Educamazônia - Educação, Sociedade e Meio Ambiente, v. 25, n. 2, p. 291-311, 2020.

CORDEIRO, K. M. de A. O impacto da pandemia na Educação: a utilização da tecnologia como ferramenta de ensino. 2020.

GIL, A. C. Métodos e Técnicas de Pesquisa Social. 6 ed. São Paulo: Atlas 2010.

MARCONI, M. de A.; LAKATOS, E. M. Técnicas de pesquisa: planejamento e execução de pesquisas, amostragens e técnicas de pesquisas, elaboração, análise e interpretação de dados. 7 ed. São Paulo: Atlas, 2008.

MALHOTRA, et al. Introdução a Pesquisa de Marketing. São Paulo: Pearson Prentice Hall, 2005.

MELO, I. V. As consequências da pandemia (COVID-19) na rede municipal de ensino:impactos e desafios. 2020. 24 p. Trabalho de Conclusão de Curso (Especialista em Docência no Ensino Superior) - Câmpus Ipameri, Instituto Federal Goiano, Ipameri, 2020.

MOREN, E. B. S.; DOS SANTOS, A. R. Uma reflexão sobre ações de formação deprofessores no Brasil. Revista Ibero-americana de Educação, v. 55, n. 1, p. 11, 2011. 
Disponível em: https://rieoei.org/historico/expe/3700Rocha.pdf. Acesso em: 17 ago. 2021.

OLIVEIRA. S. F. Pedagogias e professores em tempos de pandemia. Pedagogia em Ação, v. 13, n. 1, 2020.

NÓVOA, A. Firmar a posição como professor, afirmar a profissão docente. Cadernos de Pesquisa, v. 47, n. 166, p. 1106, 2017. Disponível em:

http://www.scielo.br/pdf/cp/v47n166/1980-5314-cp-47-166-1106.pdf. Acesso em: 03 ago. 2021.

PERES, M. R. Novos desafios da gestão escolar e de sala de aula em tempos de pandemia. Revista Administração Educacional - CE - UFPE, v. 11, n. 1, p. 20-31, 2020.

Como citar este artigo (Formato ABNT):

SILVA, Felipe Ribeiro da; LUCENA, Fabiana Alves de; SOUSA, Maria do Socorro Cordeiro de Sousa. Os Desafios do Professor no Século XXI: A Tecnologia como uma Aliada no Processo Ensino e Aprendizagem. Id on Line Rev. Psic., Outubro/2021, vol.15, n.57, p. 769-778, ISSN: 1981-1179.

Recebido: 01/09/2021;

Aceito 28/10/2021;

Publicado em: 31/10/2021. 